\title{
The Relationship between Learning Motivation and Demographic, Socio- Emotional Aspects among Arab Minority Preservice Teachers in Israel
}

\author{
Dallasheh, Waleed ${ }^{1 *}$, Zubeidat, Ihab ${ }^{2}$ \\ ${ }^{1,2}$ The College of Sakhnin - Academic College for teacher Education. Sakhnin, Israel. \\ *waleed.dall@gmail .com
}

\begin{abstract}
Learning motivation means driving influences from internal (intrinsic) or external (extrinsic) forces that give learners power to learn effectively, implicating processes of learning engagement. This study examines the differences in learning motivation levels among preservice teachers in the Arab minority in Israel according to demographic and socio-emotional aspects, and the relationships between level of learning motivation and various socio-emotional characteristics. 543 Arab minority students of education (with different majors) were chosen by means of random cluster sampling, and were asked to fill out questionnaires. The findings indicated significant differences in the level of the students' learning motivation for only two demographic variables: study program and specialization. Significant negative relationships were found between learning motivation and depression and social anxiety, and significant positive relationships were found between learning motivation and perceived social and family support and self-esteem. Multiple regression results revealed that the most significant factors that explained the variance of learning motivation among Arab minority preservice teachers were perceived social and family support (13.5\%), followed by social anxiety $(1.9 \%)$, and self-esteem $(1.1 \%)$. These findings contribute to the understanding of the nature of the relationship between learning motivation and other demographic and socio-emotional aspects of preservice teachers from Israeli Arab society.
\end{abstract}

Keywords

Learning motivation; Socio- emotional aspects; Preservice teachers; Arab minority.

\section{Introduction}

Positive socio-emotional and educational-learning experiences help students to make progress throughout their years as students, and affect their mental-social adaptation in an academic atmosphere. In this context, learning motivation is an important element. In recent decades, increasingly more research attention has been paid to the role of motivation processes in successful learning (Hyunjin \& YoonJun, 2014; Jianzhong, 2014; Roness \& Smith, 2010) in the context of demographic-personal and socio-emotional aspects among both adult students, and children and adolescents (Dag, 2011; Hartnett, George, \& Dron, 2011). Most studies used sociodemographic variables such as gender, age, marital status and income, and found significant relationships between learning motivation and social anxiety, depression, social and antisocial behavior, selfesteem, learning behavior, use of psychoactive substances, etc. Investigation of emotional-social aspects according to demographic data and the relationships between them among preservice teachers is a novelty in the academic world. Researching the issue could be of importance to the academic, social and personal functioning of education students.

The main hypothesis of the current research was that relationships would be found between demographic-personal and socio-emotional aspects and learning motivation among preservice teachers (most of them women) in the Arab minority in Israel, and that the variance of learning motivation could be explained by various demographic and socio-emotional characteristics. This hypothesis raised the following questions:

1.Would we find differences in the levels of learning motivation among Arab minority students of education according to demographic characteristics?

2.What is the relationship between socioemotional characteristics and the learning motivation of Arab minority students of education?

The literature review focuses first on describing the variable that is at the heart of this study learning motivation, followed by a review of two aspects that could, according to the literature, be related to education students' motivation; namely, demographic socio-emotional characteristics. 


\section{Literature Review}

\section{Learning Motivation}

The term 'motivation' refers to passion, driving force, or even compulsion, which survives even if it entails difficulties, high costs, or failure, and is therefore an important element of the learning process (Caroline \& Simone, 2010; Gaby \& Kasumi, 2015; Hartnett, George, \& Dron, 2011; Kaplan, Katz, \& Blum, 2011; Kumazawa, 2013). Indeed, the scientific literature points to a relationship between one's level of motivation and final outcomes (Chiung-Sui et al., 2014; Lages, Emygdio, Monte, \& Alchieri, 2015). In recent decades, the key role of motivation processes in the success of students has been increasingly acknowledged (Hyunjin \& YoonJun, 2014; Jianzhong, 2014; Shavit \& Reiter, 2016; Westra, 2012; Whitaker, Graham, Severtson, Furr-Holden, \& Latimer, 2012).

Researchers have asked why a certain individual is driven by intrinsic motivation even though external rewards given to learners generate a significant behavior change. Their reply is that rewards create only a temporary, passing change (Hardman, Horne, \& Lowe, 2011). Furthermore, some argue that external rewards are more harmful than beneficial, because they damage one's intrinsic motivation (Deci, Koestner, \& Ryan, 1999). From time immemorial, teachers have struggled to expedite and encourage their students' learning processes by increasing their intrinsic motivation (Brophy, 2008; Froiland, 2010). Intrinsic motivation opens a window of opportunity for enjoyable, interesting and relevant learning for the sake of the learners' psychological needs (Ryan \& Deci, 2000).

Usually, the performance of students with high intrinsic motivation improves with time (Shernoff \& Csikszentmihalyi, 2009). For instance, they experience positive feelings when they do homework (Froiland, 2011), which positively affects their sense of mental wellbeing (Deci \& Ryan, 2008; Gottfried, 1990). Scholars found that the higher students' intrinsic motivation was, the less they were likely to drop out of school (Vallerand \& Bissonnette, 1992), and that intrinsic motivation had a significant effect on schoolchildren's performance and their happiness index (Froiland, Smith, \& Peterson, 2012; Grant, 2008).

Ryan (1995) proposed five types of regulation, which are five levels of learning motivation: a. extrinsic regulation - investing effort out of fear of punishment or hope for reward; b. introjected regulation - investing effort involving coercion out of fear of rejection, in hope of achieving esteem and belonging to a social status; c. identified regulation - investing effort following identification of necessary, moral action with a clear rationale; $d$. integrated regulation - investing effort that facilitates the realization of personal goals and values; e. intrinsic regulation investing effort out of enjoyment and interest, and exhibiting conflict-free emotions.

The relationship between learning motivation processes and students' social goals is still being investigated, with dichotomous distinction between two orientations of goals: the approach orientation, which describes situations in which the student is directed and driven to positive results, and avoidance orientation, which describes situations in which the student is directed and driven to negative results (Alex \& Jennifer, 2014; Elijah-Mensah, 2009; Gaby \& Kasumi, 2015; Inceoglu, Segers, \& Bartram, 2012).

The main aspects that were found to correspond with the individual's motivation level are divided into two groups: personal demographic characteristics (such as gender, age, social and ethnic background) and socio-emotional characteristics.

\section{Socio-emotional Aspects}

Self-esteem, social anxiety, depression, and perceived social and family support are socioemotional aspects that the scientific literature links with the academic world of preservice teachers. The following describes these concepts and relevant research.

Self-Esteem. Self-esteem is defined as an organized set of characteristics that one attributes to oneself and acts accordingly (Fitts, 1965). The professional literature presents self-esteem as the individual's perception of him- or herself, which is constantly reinforced, and is perceived as self- 
judgement based on experiences of success or failure. This judgement can explain a long and varied list of behaviors such as obedience, morality, changing attitudes, interpersonal attraction, perversions, and help-giving (Kumazawa, 2013; Lages et al., 2015; Westra, 2012). The social identity theory, which deals with the individual's collective context, places social-cultural and ethnic characteristics at the heart of forming one's self-esteem (Smith, Walker, Fields, Brookins, \& Seay, 1999). Some see selfesteem as cause and effect of social-cultural factors (Taylor, Wooten, Babcock, \& Hill, 2002), and others add that in minority groups, selfesteem is perceived both as one's evaluation of belonging to an ethnic group and as a criterion of social acceptance and emotional experiences (Hartnett et al., 2011; Verkuyten \& Nekuee, 2001).

Various scholars addressed the relationship between self-esteem and motivational orientation to learning. Specifically, the more dominant one's academic self-esteem as an active self-image is, the more he or she intensifies learning activities to fulfil learning goals. Positive academic selfesteem predicts higher learning motivation and achievements than other measures of self-esteem. However, to understand the relationship between academic self-esteem and adaptation to learning, we must consider the academic ability of other students in the immediate learning environment. High academic self-esteem students advance their perceptions toward the approach orientation as a reward that reinforces intrinsic motivation, efficacy, and internal attribution of the achievement. On the other hand, low academic self-esteem students develop avoidance orientation, which is a negative predictor of intrinsic motivation, and perceive their personal ability as low compared to others (Cameron, Pierce, Banko, \& Gear, 2005; Caroline \& Simone, 2010; Conroy \& Elliot, 2004; Jianzhong, 2014; Roness \& Smith, 2010; Shavit \& Reiter, 2016; Westra, 2012).

Social Anxiety. The DSM defines social anxiety as "marked fear or anxiety about one or more social situations in which the individual is exposed to possible scrutiny by others... The fear or anxiety is out of proportion to the actual threat posed by the social situation and to the sociocultural context" (American Psychiatric Association, 1994, 2013). People who suffer from social anxiety are afraid of others' negative assessment in various social situations that require social performance and interaction with others. Moreover, those who suffer from social anxiety are not assertive, find it hard to participate in social gatherings and speak in public, to cope with authority figures, and to initiate new relationships, which leads to limited social contacts (Bjornsson et al., 2011; Obeid, Buchholz, Boerner, Henderson, \& Norris, 2013).

The incidence of additional psychopathological disorders among people with social anxiety increases the severity of anxiety reactions and low self-esteem, and reduces their learning motivation and, consequently, academic achievements (Roca \& Baca, 1998). It was found that $37.7 \%$ of people who suffer from social anxiety reported significant impairment of at least one functional area - academic, personal, or work-related compared to people with other social disorders (Stein, Torgrud, \& Walker, 2000). Another study found that people who suffer from social anxiety express significant deficiency in either the social, academic or professional sphere (Schneier et al., 1994).

Social anxiety is also negatively related to quality of life (McShane, Walter, \& Rey, 2004), and mental health (Kashdan, 2002). A study that examined 961 students in Spain found that adolescents, who suffered from low self-esteem and evaluated themselves as failing, had a higher average on the variables of depression-anxiety, criminal behavior, violent behavior, attention disorders, and communication problems with others than those who evaluated themselves as successful (Zubeidat, Fernández-Parra, Sierra, Vallejo, \& Ortega, 2009). These findings emphasize that social anxiety has a negative impact on academic performance.

The literature that shows a direct relationship between learning motivation and social anxiety is sparse. The few existing studies indicate that students with high self-esteem are more active in the classroom than low self-esteem students are, because their intrinsic motivation for such 
classroom involvement is higher (Phillips, Smith, $\&$ Modaff, 2001). Another study found a positive relationship between social efficacy and learning motivation among students, and a negative relationship between their social efficacy and social anxiety (Magelinskaite, Kepalaite, \& Legkauskas, 2014).

Depression. Depression is defined as a reaction pattern characterized by persistent feelings of sadness and hopelessness accompanied by low self-esteem, and loss of interest in once enjoyable activities (American Psychiatric Association, 2013). Depression is a recurring disease, and each episode increases the risk of another (Duckworth, Gruttadaro, \& Markey, 2010). There are a number of causes of depression including social and biological changes experienced by the individual (Thapar, Collishaw, Pine, \& Thapar, 2012), and the socioeconomic status of their families (Goodman, Slap, \& Huang, 2003).

A relationship was found between adolescents' depression and the following phenomena: increased emotional and behavior problems, educational and social impairment, smoking, abuse of addictive substances, and obesity (Jaycox et al., 2008). It seems that the parents' attachment style with their children crucially affects the onset of depression in children. In this context, a significant relationship was found between low self-esteem and depression (Nunley, 1996).

The effects of depression are critical, and include changes in normative behavior, impaired academic functioning, concentration problems, lack of appetite, neglect of external appearance, profound self-criticism, a sense of worthlessness and helplessness, overreaction to criticism, prolonged insomnia, changes in mood, sleep patterns and energy, as well as decreased enjoyment of life, self-mutilation, social isolation, low academic achievements, and frequent absenteeism (Black Dog Institute, 2012); in severe cases, depression can lead to suicide, which is the main cause of death among 15-24-year-olds who suffer from the disorder.

Perceived social and family support. Social support is defined as a set of specific behaviors perceived by the individual as contributing to his or her physical and mental wellbeing (Malecki \& Demaray, 2002). When individuals believe that others will provide support in the form of the social resources that they need, it considerably and even significantly improves both their ability to cope with demands and expectations and their emotional and physiological reactions. Social support affects the individual's health in many varied ways including improved thoughts, emotions and behaviors, moderates negative behaviors, and increases behaviors that promote health (Callaghan \& Morrisey, 1993).

The anthropological research literature more or less agrees that the term 'family' incorporates socioeconomic and symbolic implications. Parental support includes a wide array of structures such as responsiveness, warmth, acceptance, and affection (Samara, 2004). The family reinforces the ties between its members by three basic principles: familiarity, understanding, and cooperation. Family support is the key element at the basis of emotional climate that affects the family's functioning in general (Barber, 2008). The strength of the connection between the family and the individual, and its effect on his or her behaviors, depends on two opposing principles: support and control. The degree of support provided by the family is expressed in attachment characterized by warmth, love and assistance, and control - by monitoring, supervision, and expectations of discipline (Reitz, Dekovic, \& Meijer, 2006).

The combination of parental support and the school's or academic institution's support is one the individual's central and important defense factors. However, sometimes we encounter parental psychopathology, i.e. symptoms of neurosis or psychosis among parents, or problematic or abnormal family functioning, unhealthy communication, and parents' inability to control their children's behavior. Such situations are risk factors for the children (Rubin, Bukowski, \& Parker, 2006).

\section{Demographic-Personal Aspects}

The main demographic-personal characteristics that were examined in the present study are: study program (regular B.Ed. studies, career change and continuing studies, pre-academic preparatory 
program, conditional students, and M.Ed. students $)$ year of studies $\left(1^{\text {st }}, 2^{\text {nd }}, 3^{\text {rd }}, 4^{\text {th }}\right)$, specialization (English, mathematics, special education, Arabic, preschool, and sciences), employed (yes/no), marital status, income (low, medium, high), ethnicity/religion (Muslim, Christian, Druze), gender, and age.

Based on the above literature review, the goal of the present study was to examine among students in an Israeli-Arab teaching college the following: a. Differences in the levels of learning motivation according to demographic-personal characteristics; b. Relationships between learning motivation and socio-emotional characteristics; and c. A predictive model of learning motivation that includes demographic-personal and socioemotional aspects. Figure 1 depicts the research model.

Figure 1. Research model: Emotional-social and demographic-personal aspects as correlates of learning motivation.

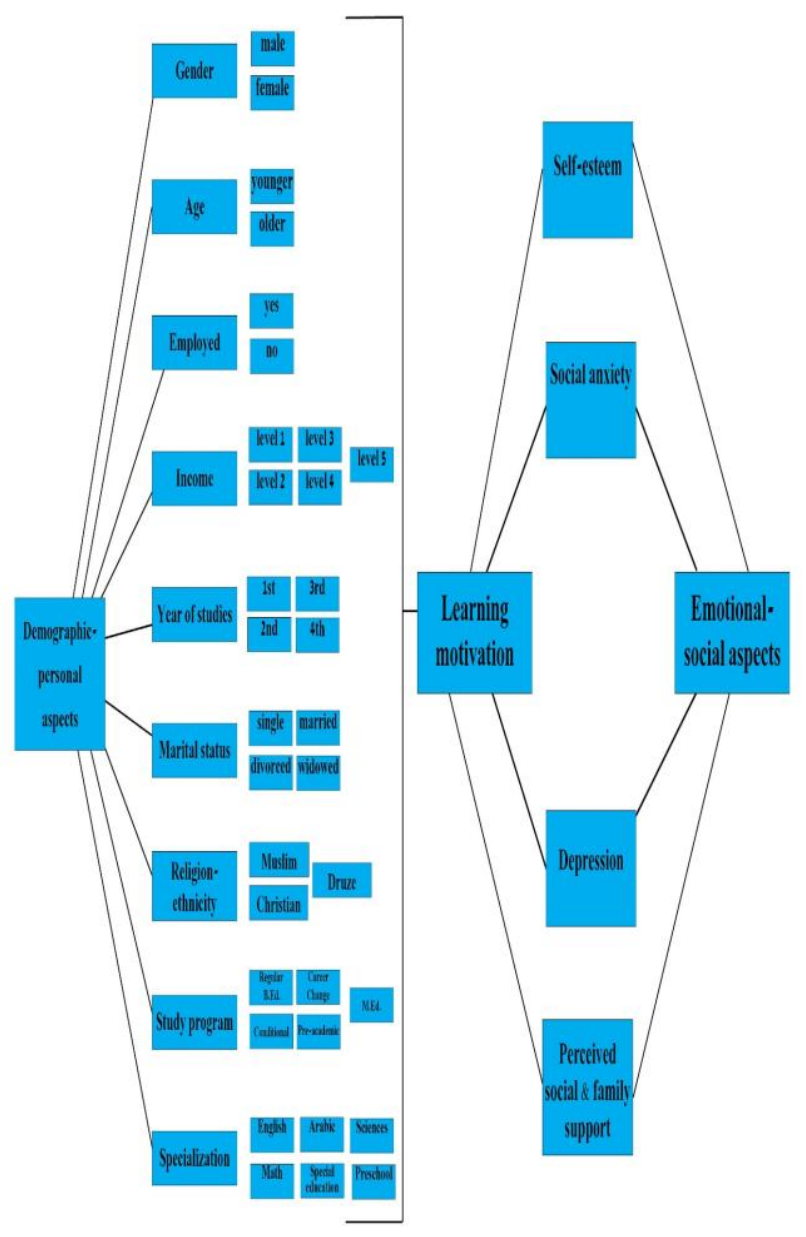

\section{Rationale and Hypotheses}

The literature review indicates that most studies on learning motivation and its demographic and personal correlates were conducted on Western student populations, less on Israeli populations, and chiefly not on education students from the Arab minority in Israel. There are even less studies of socio-emotional and demographicpersonal aspects that characterize students' learning motivation, and almost no studies of this kind on preservice teachers - all of which motivated us to conduct this study.

\section{Hypotheses}

1. Differences will be found in the learning motivation of students in an Arab minority teaching college according to the groups they belong to defined by various demographic aspects: gender, age, employment, marital status, year of studies, income, religious-ethnic background, study program, and specialization.

2. Relationships will be found between the Arab education students' socioemotional characteristics and their learning motivation as follows:

a. Negative relationship between depression and learning motivation

b. Positive relationship between perceived social and family support and learning motivation

c. Negative relationship between social anxiety and learning motivation

d. Positive relationship between self-esteem and learning motivation.

\section{Methodology}

\section{Participants}

The participants in this study were 543 students at an Arab minority education college, who studied in a number of programs (pre-academic preparatory program, conditional students, regular B.Ed. students, M.Ed. students, career change and continuing students), and in a number of 
specializations or majors (Arabic, English, math, preschool, and special education). All participants' native language was Arabic. The vast majority of the participants were female B.Ed. students; however, there were more men than women in the career change to teaching and continuing studies programs. The sample was selected through random cluster sampling. The number of participants (543) is a large enough sample to provide the required variance. The variety of the sample was in the differences in age, marital status, socioeconomic circumstances, study program, and religious-ethnic background. It should be noted that the distribution of the participants according to gender and religiousethnic background was not equal $(91.8 \%$ women vs. $8.2 \%$ men; $89.5 \%$ Muslim, $8.3 \%$ Christian, $2.2 \%$ Druze). The mean age of the participants was 23.59 ( $\mathrm{SD}=6.041)$.

\section{Research Setup}

This is in principle a quantitative research, and correlational by nature. It attempts, on one hand, to examine the differences in learning motivation of preservice teachers in the Arab minority by demographic-personal factors, and, on the other hand, to investigate the relationship between the result variables and the students' socio-emotional and demographic-personal characteristics. Therefore, the dependent variable is learning motivation, and the independent variables are: gender, age, study program, year of studies, employment, marital status, socioeconomic situation, religious-ethnic background, depression, perceived social and family support, social anxiety, and self-esteem.

\section{Instruments}

Demographic Questionnaire: This questionnaire included demographic background questions such as gender, age, etc.

Motivation and Attitudes to Studies: The 15 items were taken from the Motivated Strategies for Learning Questionnaire (MSLQ) (Pintrich, Smith, Garcia, \& McKeachie, 1987). Respondents responded on a Likert scale of 1 (not at all true of me) to 7 (very true of me). Sample items: " I think that what we are learning in this class is interesting", or "It is very important for me to learn what is being taught in this class". The questionnaire measures motivational beliefs regarding studies in a certain program, and examines the students' learning strategies in that program. Replies assess the students' level of learning motivation. The questionnaire measures three factors: intrinsic orientation to perform, value of the task, and critical thinking. Cronbach's alpha of the MSLQ was 0.88 .

Rosenberg's Self-esteem Questionnaire (Rosenberg, 1965): is a scale of 10 items that examine self-esteem. Respondents are requested to express their agreement with statements on a 1 (strongly agree) to 4 (strongly disagree) Likert scale. Sample items: "I feel that I have a number of good qualities", " I feel I do not have much to be proud of", and " I wish I could have more respect for myself ". The analysis produces two factors: positive esteem and negative esteem. It should be noted that items 3, 5, 8, 9, 10 were reverse coded. Cronbach's alpha for Rosenberg's self-esteem scale was 0.76 .

Beck Depression Inventory (Beck, Ward, Mendelson, Mock, \& Erbaugh, 1961): This questionnaire is one of the most common tools to measure the severity of depression. The tool, developed by Aharon Beck, founder of the cognitive treatment approach, is based on a multiple-choice questionnaire with 21 self-report items. Respondents reply on a 0 to 3 Likert scale. Sample items: "I don't cry any more than usual", "I don't have any thoughts of killing myself", and "I can sleep as well as usual". Developing a measuring tool in psychology produced a major change in professionals' perceptions, who had considered depression as a phenomenon rooted in one's thoughts. The BDI version that is use today is designed for subjects over the age of 13 , and includes depression symptoms such as hopelessness and irritability, guilt and punishment thoughts, fatigue, weight loss, and disinterest in sex. Cronbach's alpha of Beck's questionnaire was 0.77 .

Liebowitz Social Anxiety Scale (LSAS) (Liebowitz, 1987): This questionnaire was designed to assess social anxiety through assessment of fear and of avoidance in social situations, and includes 24 items: 13 items describe performance situations, and 11 describe social interactions. Each statement that points to fear/anxiety was coded from 1 (none) to 4 
(severe), and avoidance was separately coded 1 (never) to 4 (usually). Sample items: "Going to a party", "Writing while being observed"; and "Speaking in front of an audience". A higher score indicates higher social anxiety. The final score is the calculated average of the respondent's answers. Cronbach's alpha of the LSAS was 0.94. Cronbach's alpha for each element - fear and avoidance - was found to be 0.91 and 0.89 , respectively.

Multidimensional Scale of Perceived Social and Family Support (MSPSS) (Zimet, Dahlem, Zimet, \& Fanley, 1988): This questionnaire includes 12 statements that examine the respondent's subjective perception of the social and family support available to him/her from three sources: family, friends, and significant others. Three measures can be derived from the MSPSS according to the average answers for each factor. The statements are scored on a 1 (very strongly disagree) to 7 (very strongly agree). Sample items: "My family really tries to help me", "There is a special person in my life who cares about my feelings". Cronbach's alpha of the MSPSS was 0.91 .

\section{Procedure}

The researchers explained the goals of the research to the students, and requested their consent to answer the questionnaires. The guidelines to filling out the questionnaires were clarified without any undue influence on the students. The questionnaires were all in Hebrew, and we saw no need to translate them into Arabic, assuming that the students understood Hebrew well. The questionnaires were collected at the college, but not during lessons, and were coded and analyzed by the researchers at a later stage. The data collection process took place during October-December 2014.

It should be noted that for ethical reasons, it was made clear to the participants that their replies were completely anonymous, and that any data they provided would be used solely for the purpose of this study, and would not be transferred to a third party. In this context, the student's consent was voluntary. We respected any student's refusal to participate.

\section{Results}

We first hypothesized that differences would be found in the learning motivation of education students in an Arab minority teaching college according to various demographic aspects: gender, age, employment, marital status, year of studies, income, religious-ethnic background, study program, and specialization. We performed t-tests for independent samples and one-way analysis of variance (ANOVA) to corroborate this hypothesis. The results are presented in Table 1.

Table 1. Comparison between the effects of the categories study program and specialization on learning motivation $(\mathrm{N}=543)$.

\begin{tabular}{llllll}
\hline Variable & Category & N & Mean & SD & F \\
\hline & Regular B.Ed. & 304 & 5.58 & 0.86 & \\
Learning & Career change & 49 & 5.19 & 1.10 & \\
motivation & Conditional & 76 & 5.53 & 0.93 & $2.93^{*}$ \\
& Preparatory & 49 & 5.51 & 0.78 & \\
& M.Ed. & 63 & 5.75 & 0.91 & \\
\hline \multirow{5}{*}{ mearning } & English & 92 & 5.47 & 0.95 & \\
& Mathematics & 55 & 5.63 & 0.74 & \\
& Arabic & 18 & 5.46 & 0.93 & \multirow{2}{*}{$2.74^{*}$} \\
& Special & 36 & 5.97 & 0.51 & \\
& education & 57 & 5.43 & 0.82 & \\
& Sciences & 57 & 5.72 & 0.81 & \\
& Preschool & & & & \\
\hline
\end{tabular}

$* \mathrm{p}<0.05$

We see a significant difference in the means of learning motivation between the five groups of study program (regular B.Ed., career change and continuing studies, pre-academic preparatory program, conditional, and M.Ed.). Since the differences were significant in all measures of variance analysis, Scheffe tests were conducted to examine which pairs of comparisons produced significant differences. The results indicated a significant difference in the means of learning motivation in one comparison - between career change students and M.Ed. students. No differences in the means of learning motivation were found in any of the other comparisons.

Table 1 also reveals a significant difference in the means of learning motivation between the six groups of specialization. Since the differences were significant in all measures of variance analysis, Scheffe tests were conducted to examine which pairs of comparisons produced significant differences. The results indicated significant differences in the means of learning motivation in 
two comparisons - between special education majors and English majors, and between special education majors and science majors. No differences in the means of learning motivation were found in any of the other comparisons.

Examination of learning motivation means for seven additional demographic-personal variables - age, employment and gender (examined by ttests), and marital status, year of studies, income and religious-ethnic background (examined by one-way ANOVA) - found no significant differences.

The second hypothesis assumed that relationships would be found between the Arab education students' socio-emotional characteristics (depression, perceived social and family support, social anxiety, and self-esteem) and their learning motivation. Pearson correlations were employed to corroborate this hypothesis. The results are displayed in Table 2.

\section{Table 2. Pearson correlation coefficients for relationships between socio-emotional aspects and learning motivation $(\mathrm{N}=543)$.}

\begin{tabular}{lllll}
\hline & Depression & $\begin{array}{l}\text { Perceived } \\
\text { social and } \\
\text { family } \\
\text { support }\end{array}$ & $\begin{array}{l}\text { Social } \\
\text { anxiety }\end{array}$ & $\begin{array}{l}\text { Self- } \\
\text { esteem }\end{array}$ \\
\hline $\begin{array}{l}\text { Learning } \\
\text { motivation }\end{array}$ & $-0.138^{* *}$ & $0.392^{* * *}$ & $-0.198^{* * *}$ & $0.219 * * *$ \\
\hline$* * \mathrm{p}<0.01 ; * * * \mathrm{p}<0.001$ & & &
\end{tabular}

The following results fully substantiate the second hypothesis:

1. A significant negative relationship between depression and learning motivation $\left(\mathrm{r}_{\mathrm{p}}=-0.138, \mathrm{p}<00.1\right)$, so that the higher the respondent's level of depression, the lower his/her learning motivation is.

2. A significant positive relationship between perceived social and family support and learning motivation $\left(\mathrm{r}_{\mathrm{p}}\right.$ $=0.392, \mathrm{p}<000.1$ ), so that the higher the respondent's perceived support, the higher his/her learning motivation is.

3. A significant negative relationship between social anxiety and learning motivation $\left(r_{p}=-0.198, p<000.1\right)$, so that the higher the respondent's level of social anxiety, the lower his/her learning motivation is.

4. A significant positive relationship between self-esteem and learning motivation $\left(r_{p}=0.219, p<000.1\right)$, so that the higher the respondent's selfesteem, the higher his/her learning motivation is.

Then, to examine which variables could predict the students' learning motivation, we conducted stepwise multiple regression analysis. We entered in the regression model the variables social anxiety, self-esteem, perceived social and family support, depression and age, i.e., all quantitative variables, as independent predictors, to examine which would significantly explain the learning motivation variance. The results are presented in Table 3.

Table 3. Stepwise multiple regression analysis results to predict learning motivation $(\mathrm{N}=543)$.

\begin{tabular}{lllll}
\hline Predictor & $\mathrm{B}$ & $\beta$ & $\mathrm{T}$ & $\begin{array}{l}\text { Accumulated } \\
\mathrm{R}^{2}\end{array}$ \\
\hline $\begin{array}{l}\text { Perceived and } \\
\begin{array}{l}\text { social } \\
\text { family support }\end{array}\end{array}$ & & & & 0.135 \\
$\begin{array}{l}\text { Social anxiety } \\
\text { Self-esteem }\end{array}$ & -0.205 & -0.112 & $-2.65 * *$ & 0.154 \\
\hline$* * \mathrm{p}<0.01 ; * * * \mathrm{p}<0.001$ & & & & \\
\hline
\end{tabular}

The results indicated that we could explain the students' learning motivation level based on the variables: perceived social and family support, social anxiety, and self-esteem. The variables depression and age were removed from the regression model, because they did not significantly explain learning motivation variance. The most significant variable that explained the learning motivation variance was perceived social and family support $(13.5 \%)$, followed by social anxiety (1.9\%), and self-esteem (1.1\%). The results in total explained $16 \%$ of the variance.

\section{Discussions}

The main goal of this study was to examine differences in learning motivation among Arab minority students of education by demographic variables, and relationships between learning motivation and various socio-emotional aspects. 


\section{Demographic Aspects and Learning Motivation}

We hypothesized that differences would be found in the learning motivation of education students in an Arab teaching college according to various demographic-personal aspects: gender, age, employment, marital status, year of studies, income, religious-ethnic background, study program, and specialization

The findings indicated no significant difference in learning motivation between younger and older students; the mean of learning motivation was almost equal between the age groups. This conclusion corroborates Inceoglu and colleagues' (2012) findings, but contradicts other results that younger students had higher levels of motivation than older students did (Elijah-Mensah, 2009). The results here could be explained by the intercultural differences of the Arab minority in Israel. Most of the students are relatively young (aged 18-21), and it is reasonable to assume that no significant differences would be found between them, as opposed to Jewish students in Israel, who begin their academic studies at an older age.

The findings regarding gender did not indicate a difference in learning motivation between men and women, as opposed to previous studies (Gaby \& Kasumi, 2015; Inceoglu et al., 2012), which found higher motivation among men. It is reasonable to assume that since the majority of students in the sample were women $(91.8 \%)$, we cannot deduce from this about the general population of Arab students in Israel. Therefore, further research should include a sample that more adequately represents this population.

The findings related to study programs did indicate a significant difference between the various groups. Further tests that compared pairs of these groups found a significant difference for one pair - career change students and M.Ed. students. Previous studies (Gaby \& Kasumi, 2015; Whitaker et al., 2012) have shown some decrease in learning motivation of students under pressure or anxiety. Specifically, higher learning motivation (compared to the other groups) was found among M.Ed. students, who usually study of their free choice and with pleasure, as opposed to conditional students, and differences were found between career change students and pre- academic preparatory program students, but further comparisons did not indicate significant differences in learning motivation.

The results regarding year of studies also indicated no differences between the groups $\left(1^{\text {st }}\right.$, $2^{\text {nd }}, 3^{\text {rd }}$, and $4^{\text {th }}$ year), as opposed to previous research (Sa'ada, 2007; Segal \& Ezer, 2009), which showed significant differences and mixed trends in learning motivation means in favor of students in advanced years, and in contrast to findings that point to increased learning motivation that comes with academic experience and practical teaching experience (Linder \& Harris, 1993; Woolfolk, Rosoff, \& Hoy, 1990).

On the other hand, results related to specialization indicated a significant difference in learning motivation between the six groups of majors. Further comparisons between pairs found significant differences between two pairs - special education and English majors, and special education and science majors. A likely

explanation is the challenge involved in choosing the special education major, which stems from a sense of mission, and the student's conscious and free choice. This explanation is compatible with abovementioned studies, which pointed to a positive relationship between students' free personal choice and their level of learning motivation.

The other demographic-personal aspects that were examined (employment, marital status, income, and religious ethnic background) produced no significant differences in learning motivation, as opposed to other studies, which found that people with low levels of learning motivation were characterized by a low socioeconomic status, unstable employment, and a high percentage of single men, women and students (Chiung-Sui et al., 2014; Elijah-Mensah, 2009; Hseih \& Schallert, 2008). It should be noted that most of the participants in the current study were female Muslim students, unemployed, single, low income, from various areas in the north of Israel. Additionally, the members of this population belong to the same culture, socialization, values, and customs. We, thus, found no significant differences in learning motivation between men and women, employed and unemployed, various 
income levels, socioeconomic statuses, or Muslims, Christians and Druze.

In summary, the above findings indicate that the first hypothesis of this study, regarding the relationship between learning motivation and demographic-personal aspects, was partially corroborated.

\section{Socio-Emotional Aspects and Learning Motivation}

The second hypothesis (including its subhypotheses) was that relationships would be found between the students' socio-emotional characteristics (i.e., depression, perceived social and family support, social anxiety, and selfesteem) and their learning motivation. Concerning depression, a significant negative relationship was found with learning motivation, so that the higher the student's level of depression, the lower his/her learning motivation was. These findings support previous studies mentioned above. Multiple regression analysis to predict learning motivation found that the variables depression and age were non-significant in predicting motivation, and they were removed by the regression model.

Regarding perceived social and family support, a significant positive relationship was found with motivation, so that the higher the individual's perceived support, the higher his/her learning motivation was. The multiple regression analysis showed that perceived social and family support explained $13.5 \%$ of the variance of learning motivation. These results are in line with previous research.

The findings concerning social anxiety indicated a significant negative relationship with learning motivation, so that the higher the student's level of depression, the lower his/her learning motivation was. This finding is consistent with other studies that reported the importance of social anxiety in predicting learning motivation among students of education. The literature emphasized the importance of motivational processes to learning and to students' socio-emotional development (Conroy \& Elliot, 2004; Lages et al., 2015; Hartnett et al., 2011). These complex processes are related to the student's behavior, and include many elements such as personal characteristics, the educational and social-cultural environment, and the student's specific conditions (Hsieh \& Schallert, 2008; Westra, 2012; Whitaker et al., 2012).

The final variable, self-esteem, was found to have a positive relationship with learning motivation, so that the higher self-esteem, the higher learning motivation was. This is in line with previous research that indicated the importance of socialcultural factors and ethnic characteristics in the forming of one's self-esteem (Dag, 2011; Karl \& Mark, 2009). The multiple regression analysis showed that social anxiety explained $1.9 \%$ of the variance of the students' learning motivation, and self-esteem explained $1.1 \%$. It can, therefore, be said that the second hypothesis was partially corroborated.

In summary, the findings of the current study were discussed through comparison to various other studies that investigated the demographic and socio-emotional aspects of learning motivation among adolescents and adults from various cultures. It would seem that the current study adds a layer to findings from the world, especially those that relate to the relationship between learning motivation and depression, perceived support, social anxiety, and self-esteem. The findings that were associated with demographic variables were partially consistent with previous research findings. Finally, we should note that the current findings emphasized the point that the studied socio-emotional and demographicpersonal aspects were considered significant in explaining the variance of learning motivation among Arab minority students of education in Israel.

\section{Conclusion}

Research of the demographic and socio-emotional aspects of learning motivation among adult students has been gaining momentum in recent years. It was, therefore, important to investigate the phenomenon of learning motivation and its relationship with these factors among preservice teachers. Our findings contribute to the understanding of the relationship between learning motivation and other characteristics of students of education - depression, perceived social and family support, social anxiety, and self-esteem. It 
was also important to us to understand the differences between students with higher and lower levels of learning motivation among students from the Arab minority. These findings illuminate a problem that is important to teachers in general and new teachers in particular, and are expected to provoke a lively discussion. The conclusions of this study, based on the findings, are:

1.

Learning motivation among M.Ed. students is higher than among conditional students.

2. Learning motivation among students who major in special education is higher than among students who major in other specializations (English, Arabic, mathematics, and sciences).

$3 . \quad$ There were no differences in learning motivation between preservice teachers from the Arab minority by gender, age, employment, marital status, income, and religious-ethnic background.

4. The socio-emotional aspects (perceived social and family support, social anxiety, and self-esteem) were significant in predicting and explaining the variance in learning motivation.

5. Learning motivation of Arab minority students of education is significantly related to their perceived social and family support.

6. Learning motivation of Arab minority students of education is significantly related to their selfesteem.

7. Learning motivation of Arab minority students of education is significantly and negatively related to their social anxiety.

8. Learning motivation of Arab minority students of education is significantly and negatively related to their level of depression.
These conclusions have prompted us to recommend that future studies investigate the demographic-personal and socio-emotional aspects of learning motivation among students of education in both Hebrew- and Arabic-speaking colleges and universities, in an attempt to help students to cope with the challenges, difficulties, and problems they might encounter during their academic studies. Future research could also strive to identify alternative teaching methods and programs that could be suitable for student populations that are at risk due to low levels of learning motivation.

\section{Limitations and Future Studies}

The present study has some limitations, primarily because it focused on one teacher training college, and on students who differ from each other in many aspects - age, marital status, socioeconomic status, study program, and religious-ethnic background. Most of the students in this sample were women, especially in the regular B.Ed. studies and the pre-academic preparatory program; there were more men than women only in the career change program. We should note that comparisons by gender and by religious-ethnic background could not produce a reliable effect due to the unequal distribution $(91.8 \%$ women vs. 8.2\% men; $89.5 \%$ Muslim, 8.3\% Christian, 2.2\% Druze), which does not represent the normal distribution in the population.

Since this was a wide-ranging study, which employed five lengthy questionnaires that required time and concentration - we were concerned that it might not be viable. Consequently, we chose the optimal time and place conditions for the students. They were told to fill out the questionnaires in their spare time, which prolonged the questionnaire collection phase. Finally, the conclusions of this study are true specifically for students of education at an Arab minority teacher training college in the north of Israel, and cannot be generalized to all the students in Israel. 


\section{Acknowledgement}

The current study was funded by the Mofet Institute - an educational research institute in Israel.

\section{References}

[1] After, A., \& Haruvi, L. (2006). Depression and suicidal behavior among adolescents. Israel: Ministry of Health. (Hebrew)

[2] Alex C.G., \& Jennifer, L. (2014). High ability students' voice on learning motivation. Journal of Advanced Academics, 25, 7-24.

[3] American Psychiatric Association (2013). Diagnostic and statistical manual of mental disorders (DSM; $5^{\text {th }}$ edition). Washington, DC: Autor.

[4] Barber, B.K. (2008). Parental psychological control: Revisiting a neglected construct. Child Development, 67(6), 3296-3319.

[5] Beck, A.T., Ward, C.H., Mendelson, M., Mock, J., \& Erbaugh, J. (1961). An inventory for measuring depression. Archives of General Psychiatry, 4, 561571.

[6] Bjornsson, A.S., Bidwell, L.C., Brosse, A.L., Carey, G., Hauser, M., Mackiewicz Seghete, K.L., Schulz-Heik, R.J., Weatherley, D., Erwin, B.A., Craighead, W.E. (2011). Cognitive-behavioral group therapy versus group psychotherapy for social anxiety disorder among college students: A randomized controlled trial. Depression and Anxiety, 28, 1034-1042.

[7] Black Dog Institute (2012). Depression in adolescents \& young people. Fact Sheet. Retrieved from: https://www.blackdoginstitute.org.au/docs/ default/source/factsheets/depressioninadol escents.pdf?sfvrsn $=2$

[8] Brent, D., Emslie, G., Fassler, D., Kratochvil, C., March, J., Robb, A., et al. (2012). The use of medication in treating childhood and adolescent depression: Information for patients and families. Prepared by the American Psychiatric Association and the American Academy of Child and Adolescent Psychiatry.

[9] Brophy, J. (2008). Developing students' appreciation for what is taught. Educational Psychologist, 43(3), 132-141.

[10] Callaghan, P., \& Morrissey, J. (1993). Social support and health: A review. Journal of Advanced Nursing, 18(2), 203210.

[11] Cameron, J., Pierce, W.D., Banko, K.M., \& Gear, A. (2005). Achievement-based rewards and intrinsic motivation: A test of cognitive mediators. Journal of Educational Psychology, 97(4), 641-655.

[12] Caroline, F., \& Simone, E. (2010). Developing beliefs about classroom motivation: Journeys of preservice teachers. Teaching and Teacher Education, 26, 1404-1415.

[13] Chiung-Sui, C., Zhi-Feng, L. E., HungYen, S., Chun-Hung, L., Nian-Shing, C., \& Shan-Sha, C. (2014). Effects of online college student's Internet self-efficacy on learning motivation and performance. Innovations in Education and Teaching International, 51(4), 366-377.

[14] Conroy, D. E., \& Elliot, A. J. (2004). Fear of failure and achievement goals in sport: Addressing the issue of the chicken and the egg. Anxiety, Stress, and Coping, 17(3), 271-285.

[15] Dag, R. (2011). TI: Still motivated? The motivation for teaching during the second year in the profession. Teaching and Teacher Education, 27, 628-638.

[16] Deci, E. L., \& Ryan, R. (2008). Facilitating optimal motivation and psychological well-being across life's domains. Canadian Psychology, 49(1), 1423.

[17] Deci, E. L., Koestner, R., \& Ryan, R. M. (1999). A meta-analytic review of 
experiments examining the effects of extrinsic rewards on intrinsic motivation. Psychological Bulletin, 125(6), 627-668.

[18] Donat, A. (2011). What is family? On definitions and alternative social relationships. 'Women who don't want children' forum, lecture at 'Gender in the field and in academia' conference, Bar Ilan University. (Hebrew)

[19] Duckworth, K., Gruttadaro, D., \& Markey, D. (2010). What families need to know about adolescent depression? NAMI (National Alliance on Mental Illness).

[20] Elijah-Mensah,

A. (2009). Motivation and Age: An empirical study of women-owners of tourism ventures in Ghana. Journal of Travel and Tourism Research (Online), p.139. Retrieved from: https://www.researchgate.net/publication/3 13557640_Motivation_and_age_an_empir ical_study_of_womenowners_of_tourism_ventures_in_ghana

[21] Fitts, W. H. (1965). Tennessee self-scale. Nashville, TN: Counselor Recordings and Tests.

[22] Froiland, J. M. (2010). A developmental, educational, and school psychologist: How the late Jere Brophy's integrative approach to children's motivation to learn can inform school-based practice. The School Psychologist, 64(3), 22-26.

[23] Froiland, J. M. (2011). Parental autonomy support and student learning goals: A preliminary examination of an intrinsic motivation intervention. Child and Youth Care Forum, 40(2), 135-149.

[24] Froiland, J. M., Smith, L., \& Peterson, A. (2012). How children can be happier and more intrinsically motivated while receiving their compulsory education. In A. Columbus (Ed.), Advances in psychology research (Vol. 87, pp. 85-112). Hauppauge, NY: Nova Science.

[25] Gaby, S., \& Kasumi, Y. (2015). The relationship between global competence and language learning motivation: An empirical study in critical language classrooms. Foreign Language Annals, 48(3), 511-520.

[26] Goodman, E., Slap, G. B., \& Huang, B. (2003). The public health impact of socioeconomic status on adolescent depression and obesity. American Journal of Public Health, 93(11), 1844-1850.

[27] Gottfried, A. E. (1990). Academic intrinsic motivation in young elementary school children. Journal of Educational Psychology, 82, 525-538.

[28] Grant, A. M. (2008). The significance of task significance: Job performance effects, relational mechanisms, and boundary conditions. Journal of Applied Psychology, 93, 108-124.

[29] Hardman, C. A., Horne, P. J., \& Lowe, C. F. (2011). Effects of rewards, peer modeling and pedometer targets on children's physical activity: A schoolbased intervention study. Psychology \& Health, 26(1), 3-21.

[30] Hartnett, M., George, S. A., \& Dron, J. (2011). Examining motivation in online instance learning environments: Complex, multifaceted, and situationdependent. International Review of Research in Open and Distance Learning, 12(6). Retrieved from: http://www.irrodl.org/index.php/irrodl/arti cle/view/1030/1954.

[31] Hsieh, P. H., \& Schallert, D. L. (2008). Implications from self-efficacy and attribution theories for an understanding of undergraduates' motivation in a foreign language course. Contemporary Educational Psychology, 33, 513-532.

[32] Hyunjin, K., \& YoonJung, C. (2014). Preservice teachers' motivation, sense of teaching efficacy, and expectation of reality shock. Asia-Pacific Journal of Teacher Education, 42, 67-81.

[33] Inceoglu, I., Segers, J., \& Bartram, D. (2012). Age- related differences in work motivation. Journal of Occupational 
and Organizational Psychology, 85(2), 300-329.

[34] Jaycox, L. H., Stein, B. D., Paddock, S., Miles, J. N. V., Chandra, A., Meredith, L. S. et al. (2008). Impact of teen depression on academic, social, and physical functioning. Pediatrics, 124, 596-605.

[35] Jianzhong, X. (2014). Regulation of motivation: predicting students' homework motivation management at the secondary school level. Research Papers in Education, 29, 457-478.

[36] Kaplan, A., Katz, A., \& Blum, H. (2011). Motivation between research and the field. Hed Ha'hinuch, 85(7), 96-98. (Hebrew)

[37] Karl, K., \& Mark, M. (2009). It is the little things: Exploring the importance of commonplace events for early-career teachers' motivation. Teachers and Teaching: Theory and Practice, 15, 43-58.

[38] Kashdan, T. B. (2002). Social anxiety dimensions, neuroticism, and the contours of positive psychological functioning. Cognitive Therapy and Research, 26, 789810.

[39] Kumazawa, M. (2013). Gaps too large: Four novice EFL teachers' self-concept and motivation. Teaching and Teacher Education, 33, 45-55.

[40] Lages, S. M., Emygdio, R., F., Monte, A. S., \& Alchieri, J. C. (2015). Motivation and self-esteem in university students' adherence to physical activity. Revista de Salúd Publica, 17(5), 677-688.

[41] Liebowitz, M. R. (1987). Social phobia. Modern Problems in Pharmacopsychiatry, 22, 141-173.

[42] Linder, R. W. \& Harris, B. (1993). Selfregulated learning: Its assessment and instructional implications. Educational Research Quarterly, 16(2), 29-37.

[43] Magelinskaite, S., Kepalaite, A., \& Legkauskas, V. (2014). Relationship between social competence, learning motivation, and school anxiety in primary school. Procedia - Social and Behavioral Sciences, 116, 2936-2940.

[44] McShane, G., Walter, G., \& Rey, J. M. (2004). Functional outcome of adolescents with 'school refusal'. Clinical Child Psychology and Psychiatry, 9, 53-60.

[45] Nunley, K. F. (1996). The relationship of self-esteem and depression in adolescence. Retrieved from: http://www.brains.org/depression.htm.

[46] Obeid, N., Buchholz, A., Boerner, K. E., Henderson, K. A., \& Norris, M. (2013). Self-esteem and social anxiety in an adolescent female eating disorder population: Age and diagnostic effects. Eating Disorders, 21, 140-153.

[47] Phillips, J., Smith, B., \& Modaff, L. (2001). "Please don't call on me": Selfesteem, communication apprehension, and classroom participation. Informally published manuscript. Retrieved from: http://murphylibrary.uwlax.edu/digital/jur/ 2001/phillips-smith-modaff.pdf.

[48] Pintrich, P., Smith, D., Garcia, T., \& McKeachie, W. (1987). A manual for the use of the motivated strategies for learning questionnaire (MSLQ). Ann Arbor, Michigan: National Center for Research to Improve Post-secondary Teaching and Learning.

[49] Reitz, E., Deković, M., \& Meijer, A. M. (2006). The structure and stability of externalizing and internalizing problem behavior during early adolescence. Journal of Youth and Adolescence, 29(3), 419-436.

[50] Roca, M., \& Baca, E. (1998). Comorbilidad psiquiátrica. In S. Cervera, M. Roca, \& J. Bobes (Eds.), Fobia social (pp. 63-96). Barcelona: Masson.

[51] Roness, D., \& Smith, S. (2010). Stability in motivation during teacher education. Journal of Education for Teaching, 36, 169-185. 
[52] Rosenberg, M. (1965). Society and the adolescent self-image. Princeton, $\mathrm{NJ}$ : Princeton University Press.

[53] Rubin, K. H., Bukowski, W., \& Parker, J. (2006). Peer interactions, relationships, and groups. In N. Eisenberg (Ed.), Handbook of child psychology: Social, emotional, and personality development (6 ${ }^{\text {th }}$ ed., pp. 571-645). New York: Wiley.

[54] Ryan, R. M. (1995). Psychological needs and the facilitation of integrative processes. Journal of Personality, 63, 397428.

[55] Ryan, R. M., \& Deci, E. L. (2000). Selfdetermination theory and the facilitation of intrinsic motivation, social development, and well-being. American Psychologist, 55(1), 68-78.

[56] Sa'ada, N. (2007). The relationship between self-direction to learning and teaching self-efficacy among education students in Arab colleges in Israel. Tel Aviv: Mofet Institute. (Hebrew)

[57] Samara, N. (2004). Teachers' evaluations of their learning-disabled students' characteristics in the Arab sector in comparison to the students' self-evaluation on measures of coherence, loneliness, and mood. Jama'a (Interdisciplinary Journal of Middle East Studies), 8, 402-421. (Hebrew)

[58] Schneier, F. R., Heckelman, L. R., Garfinkel, R., Campeas, R., Fallon, B. A., Gitow, A., Street, L., Del Bene, D., \& Liebowitz, M. R. (1994). Functional impairment in social phobia. Depression and Anxiety, 4, 126-133.

[59] Segal, S., \& Ezer, H. (2009). Stress in teacher training and its implications on the teacher trainee. Tel Aviv: Mofet Institute. (Hebrew)

[60] Shavit, P., \& Reiter, S. (2016). "I'm a partner!" Humanistic education for selfdetermination and self-advocacy. Tel Aviv: Mofet Institute. (Hebrew)
[61] Shernoff, D. J., \& Csikszentmihalyi, M. (2009). Flow in schools: Cultivating engaged learners and optimal learning environments. In R. C. Gilman, E. S. Heubner, \& M. J. Furlong (Eds.), Handbook of positive psychology in schools (pp. 131-145). New York: Routledge.

[62] Smith, E. P., Walker, K., Fields, L., Brookins, C. C., \& Seay, R. C. (1999). Ethnic identity and its relationship to selfesteem, perceived efficacy and pro-social attitudes in early adolescence. Journal of Adolescence, 22(6), 867-880.

[63] Stein, M. B., Torgrud, L. J., \& Walker, J. R. (2000). Social phobia symptoms, subtypes, and severity. Archives of General Psychiatry, 57, 1046-1052.

[64] Taylor, E. R., Wooten, R., Babcock, B., \& Hill, F. (2002). A metaphorical story to raise relational esteem in Mexican American families of low socioeconomic status. Family Journal, 10, 27-33.

[65] Thapar, A., Collishaw, S., Pine, D. D., \& Thapar, A. K. (2012). Depression in Adolescence. Lancet, 379, 1056-1067.

[66] Vallerand, R. J., \& Bissonnette, R. (1992). Intrinsic, extrinsic, and motivational styles as predictors of behavior: A prospective study. Journal of Personality, 60(3), 599620.

[67] Verkuyten, M., \& Nekuee, S. (2001). Selfesteem, discrimination, and coping among refugees: The moderating role of selfcategorization. Journal of Applied Social Psychology, 31(5), 1058-1075.

[68] Westra, H. A. (2014). Motivational interviewing in the treatment of anxiety. Kiryat Bialik: Ach. (Hebrew; translated by Dorit Sarig)

[69] Whitaker, D., Graham, C., Severtson, S., Furr- Holden, C., \& Latimer, W. (2012). Neighborhood \& family effects on learning motivation among urban African American middle school youth. 
Review Article

Journal of Child and Family Studies, 21(1), 131-138.

[70] Woolfolk, A. E., Rosoff, B., \& Hoy, W. (1990). Teachers' sense of efficacy and their beliefs about managing students. Teaching and Teacher Education, 6, 137148.

[71] Zimet, G. D., Dahlem, N. W., Zimet, S. F., \& Farley, G. K. (1988). The multidimensional scale of perceived social support. Journal of Personality Assessment, 52, 30-41.

[72] Zubeidat, I., Fernández-Parra, A., Sierra, J. C., Vallejo, M. A., \& Ortega, J. (2009). Características psicosociales y psicopatológicas en adolescentes españoles a partir del Youth Self-Report/11-18. Anales de Psicología, 25, 60-69. 